\title{
The Fukushima nuclear disaster and its effects on media framing of fission and fusion energy technologies
}

\author{
Luísa Schmidt, Ana Horta, Sérgio Pereira, \\ Ana Delicado ${ }^{1}$
}

\begin{abstract}
This paper presents results of a comparison of media coverage of fusion and fission energy technologies in three countries (Germany, Spain and Portugal) and in the English language international print media addressing transnational elite, from 2008 to 2012 . The analysis showed that the accident in Fukushima in March $\mathbf{2 0 1 0}$ did not have significant impact on media framing of nuclear fusion in the major part of print media under investigation. In fact, fusion is clearly dissociated from traditional nuclear (fission) energy and from nuclear accidents. It tends to be portrayed as a safe, clean and unlimited source of energy, although less credited when confronted with research costs, technological feasibility and the possibility to be achieved in a reasonable period of time. On the contrary, fission is portrayed as a hazardous source of energy, expensive when compared to research costs of renewables, hardly a long-term energy option, susceptible to contribute to the proliferation of nuclear weapons or rogue military use. Fukushima accident was consistently discussed in the context of safety problems of nuclear power plants and in many cases appeared not as an isolated event but rather as a reminder of previous nuclear disasters such as Three Miles Island and Chernobyl.
\end{abstract}

\section{Introduction}

TH HE accident in Fukushima Daiichi nuclear power plant on March $11^{\text {th }}, 2011$, reawakened the public anxiety of nuclear catastrophes, compelling some countries to urgently revise their nuclear power plants security systems. The European Union underlined the importance of this procedures arguing that "the safety of all EU nuclear plants should be reviewed, on the basis of a comprehensive and transparent risk and safety assessment ("stress tests. Also in the USA, India, Russia, South Korea and several other countries, the need to conduct safety tests following the lessons learned from Fukushima scaled to the top of the political agendas, while institutional support to the continuance or even expansion of the nuclear industry remained undisputable.
At the national decision level, the accident in Japan had different repercussion in each EU Member States. In France, the second largest nuclear powerproducing country, the government reaffirmed their support to the nuclear energy, while stating their commitment to conduct the EC stress tests and increase the endorsement of renewable energy sources.

By contrast, the German Federal Government announced their decision to completely phase out of nuclear energy until 2022, as a reaction to the chain of events startedin Fukushima but also as a follow-up to the country's changing energy policy - the "Energiewende" or energy transition. In Spain, after a period of uncertainty, the government approved the extension of licenses to several nuclear facilities including the oldest ones, while in the United Kingdom, Finland, Sweden and Hungary, plans to maintain or even expand nuclear capacity were unshaken by the events in Japan (World Energy Council, 2012: 16-19).

As important it is to understand the political consequences of Fukushima, we cannot disregard the general public views about this landmark event in the history of nuclear technology - that represents the risk of modernity beyond comparison: "tremendous (...) potentially catastrophic, feared and serious (certainly fateful)" (Slovic et al 2007, 117). Indeed, nuclear technology, even when it is used for peaceful ends has been a major source of controversy, and that the general public looks at nuclear technology and nuclear accidents with different lenses from those of politicians and nuclear industry stakeholders.

For what concerns nuclear fusion the main question arising from Fukushima is whether the accident has contributed to shape with different contours the image of this technology, namely in comparison to nuclear fission. SERF studies have shown that unlike fission, nuclear fusion is still unknown by the general public: as shown in a Eurobarometer survey, $58 \%$ of European citizens have heard about nuclear fusion in the context of energy production, but only $9 \%$ have heard about ITER - the largest experimental 
programme on nuclear fusion - which indicates that the knowledge about this technology is to a great extent very imprecise". (Eurobarometer, 2007). Much of the media attention given to it is driven either by scientific breakthroughs and technological developments (Borrelli, 2004) or by general expectations created around issues such as applications to host fusion research facilities on national territories, as it happened in the town of Vandellós, in Spain, at the time of the siting of the ITER research device (Prades et al., 2007). More importantly, these studies revealed that the general public frequently confuses fusion with fission and that this relationship has a negative impact on social acceptability of fusion energy (Schmidt et al., 2013b). The nuclear accident in Fukushima, which happened in a fission based nuclear power plant, reinforced the importance of this misleading association with regard to the prospects of improving public communication on fusion, as negative associations and imagery related to conventional nuclear energy (fission) may contribute to stigmatize fusion technology (HorlickJones et al., 2010).

The main hypothesis of our research is that the accident in Fukushima impacted negatively in the public image of conventional nuclear power, while contributing to highlight the debate over fusion technology as an alternative route to nuclear energy production. It was also important to evaluate if representations of fission energy conveyed in the media after Fukushima had a negative effect in shaping the public image of fusion energy. Overall, this analysis provides a contribution to understand the social construction of nuclear power imagery in contemporary societies (Schmidt et al., 2013b).

This paper is based on a research project funded by the European Fusion Development Agreement (EFDA) which consisted in an international comparison of media coverage of fusion and fission energy in three countries (Germany, Spain and Portugal) and in English language newspapers that address transnational elite. The awareness that a successful nuclear fusion programme depends largely on broad social acceptance besides scientific and technological breakthroughs, was the main reason behind the development of a series of studies on the subject of Socio-Economic Research on Fusion (SERF), founded by the Euratom back in 1997 and currently under the coordination of EFDA [1]. One important line of research in SERF studies is the confrontation between fusion and other energy technologies such as traditional nuclear or fission.

\section{MEDIA AND PUBLIC UNDERSTANDINGS OF NUCLEAR ENERGY} TECHNOLOGIES

Public acceptance of technologies has been considered a critical condition for its development and diffusion (Devine-Wright, 2007). A common assumption among policy makers and scientists is that informed citizens will be more likely to lend their support to new or controversial technologies. However, this assumption has been challenged by research showing that risk perception is a complex process involving multiple elements, and it is not clear that information leads to acceptance. In fact, public support of energy technologies is influenced by multiple factors, including pre-existing knowledge, attitudes, emotions, values, norms, beliefs, peer's opinions, trust and mass media information (Hobman and Asworth, 2013). Furthermore, a "new realism about the strengths and limitations of science" (Grove-White, 2005: 23) has emerged, resulting from the recognition of wide uncertainties related to the risks of technological innovation.

Nuclear energy production (fission) is an example of a highly stigmatised technology (Flynn, 2003) that at the beginning of its development was framed as a symbol of technological progress. As shown by Gamson and Modigliani (1989), until the 1970s there was no anti-nuclear discourse in the mass media, but this positive frame shifted into negative ones after the accidents with nuclear power plants in Three Mile Island and Chernobyl. Together with public antinuclear protests in Western Europe and the development of environmental movements, public responses to nuclear energy became often strongly negative (Flynn et al, 1998), focusing on concerns over its risks (related to accidents, terrorism and weapons) and radioactive waste. The prior belief in the dominance of science over nature has been facing tensions and gaps among policy-makers, citizens, scientists and corporations perceptions of technological innovation risks and perils, together

[1] EFDA during FP7 - Reinforced coordination of physics and technology in EU laboratories Part 7, retrieved from EFDA: http://www.efda.org/newsletter/efda-during-fp7-\%E2\%80\%93-reinforcedcoordination-of- physics-and-technology-in-eu-laboratories-part-7-2/ 
with growing distrust of political authorities and scientific expertise (Jasanoff, 2005). In the struggles for shaping public views of nuclear energy, authorities have often been accused of "secrecy" or dissemination of "biased" information, instead of "objective" information about nuclear risks (Topçu, 2008).

Fusion energy, on the contrary, is still at a research and development stage, and thus seems to benefit from a media coverage that, as in the case of other emerging technologies, tend to be positive, emphasizing scientific progress and economic prospects (Nisbet and Lewenstein, 2002), as publicly promoted by the actors mainly interested in its development.

According to Jasanoff (2005), based on Goffman's concept of framing (1974), a sense of security towards disruptive events can be created by the construction in the policy arena of cognitive frames, stories told that help making sense of experience. The analysis of media framing can thus be used to understand the construction of public views about matters such as risk perception, social representations and valuations about nuclear energy and nuclear disasters.

\section{Methodology}

The scope of our analysis on media coverage includes the number and evolution of articles published, thematic frames, actors and actors' positions, depth of information about each subject, degree of association with nuclear accidents, especially Fukushima, and image construction (perception and representations) both for fusion and fission in 2008-12. The research carried out in Portuguese, Spanish and transnational print media contexts comprised the analysis of articles about fusion and fission energy. For German media analysis, only articles about fusion were considered. With regard to fusion, the analysis encompassed a collection of articles published by nationalbased print media and English language quality newspapers and magazines aimed at the transnational elite (henceforth "transnational print media"), between the first quarter of 2008 and the third quarter of 2012. All types of newspapers and magazines were included in each study case: 20 newspapers or magazines in Germany, 20 in Spain, 15 in Portugal and 8 in the transnational print media. The titles selected for the transnational print media included The Observer, Guardian, The Washington Post, International Herald Tribune and News Statement; Forbes, The Economist and The Wall Street Journal. With regard to fission, the analysis covered a sample of national-based mainstream newspapers and English language quality newspapers, between the first quarter of 2010 and the third quarter of 2012, complying with the one year before/one year after Fukushima timeframe. The articles in Portugal were collected from eight newspapers, in Spain from three newspapers and in the transnational print media, from four main titles. The latter were: The Economist, The Observer, International Herald Tribune and New statesman. The study followed two different methods of analysis. Firstly, the articles were submitted to quantitative analysis which was designed to measure the frequency of issues or topics, messages and events presented in several types of media communications (Macnamara, 2005). Then a qualitative content analysis was employed for a sub-sample of articles in order to provide an in-depth understanding of the public representations about fusion and fission energies as conveyed by social media. (Schmidt et.al., 2013b: 9-13).

\section{Media coverage And thematic framing of Fusion}

\section{AND FISSION}

Media coverage of nuclear fusion (Figure 1) was very irregular and provided a low number of articles throughout the whole period of analysis in all study areas, except in Germany where a considerable amount of news was published in almost every quarter, mainly in the second quarter of 2011, right after the nuclear accident in Fukushima.

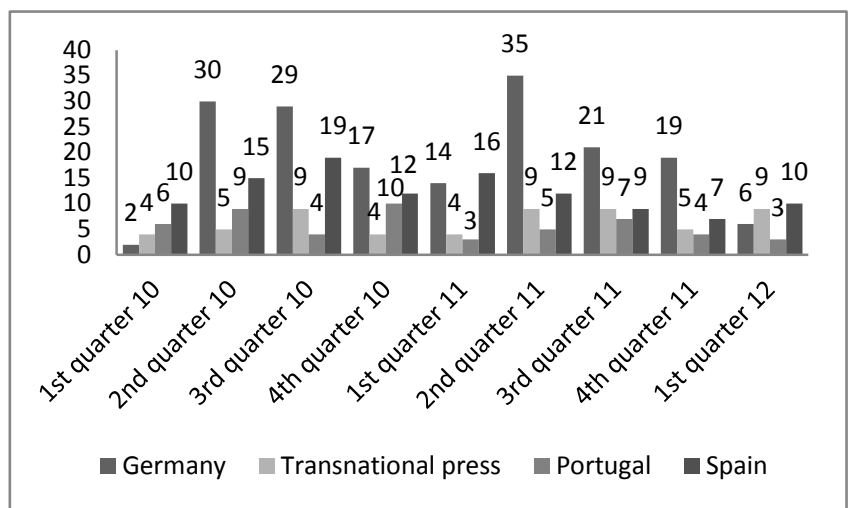

Fig. 1. Evolution of the number of articles with fusion energy related content

Fusion is framed firstly as a science and technology topic: text news about research projects and results of fusion science are the core issues of media coverage of fusion energy, a trend that has been stressed by previous studies on public perceptions of nuclear fusion (Borrelli, 2004). At a second level, fusion is linked to political subjects, mainly in Germany, but clearly dissociated from safety, environmental and climate change related themes (Figure 2). 


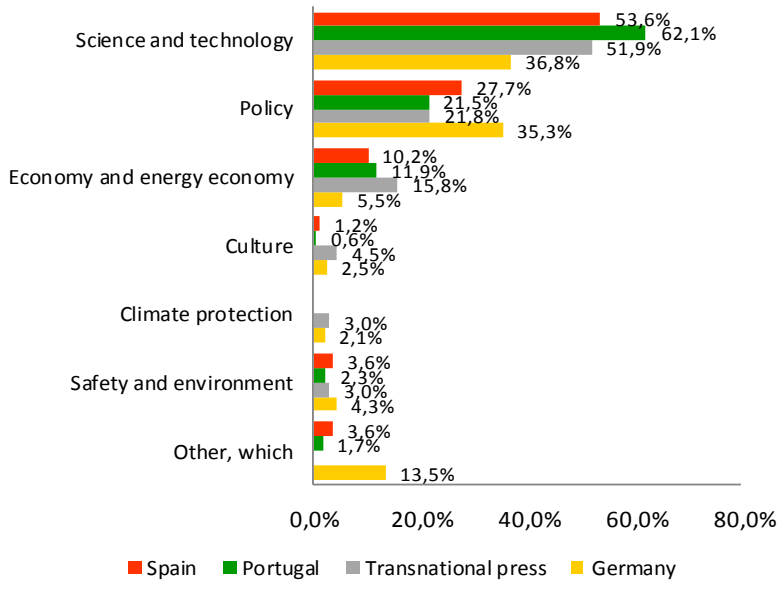

Fig. 2. Thematic areas covered in articles with fusion energy related content

The publication of articles about conventional nuclear (or fission) energy was very regular at a low degree throughout 2010, increasing considerably in the first and second quarters of 2011 as a result of the accident in Fukushima and its aftermath. From the second quarter of 2011 onward, there is a continuous decrease in the number of articles published, as media focus on the accident gradually diminished (Figure 3).

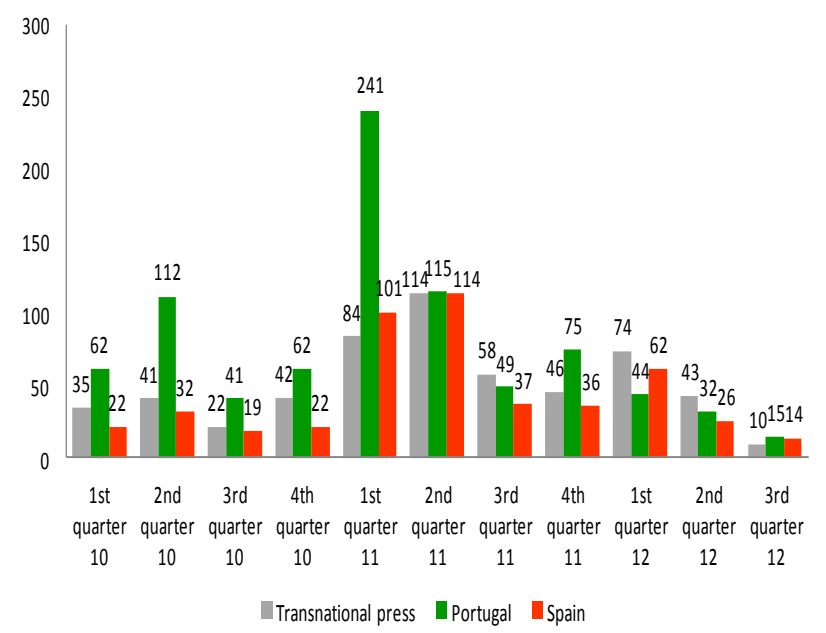

Fig. 3. Evolution of the number of articles with nuclear energy related content.

Policy related content is the main source of interest in media coverage of nuclear energy (Figure 4), followed by safety and environmental themes (more commonly presented in Spanish print media). Science and technology topics, along with economy and energy economy, do have some relevance, especially in the transnational print media, while climate protection issues are almost disregarded, although after the last decade nuclear energy has been promoted as an instrument of mitigation of climate change, both by scientists (Sailor et al 2005) and politicians (Bang 2010).

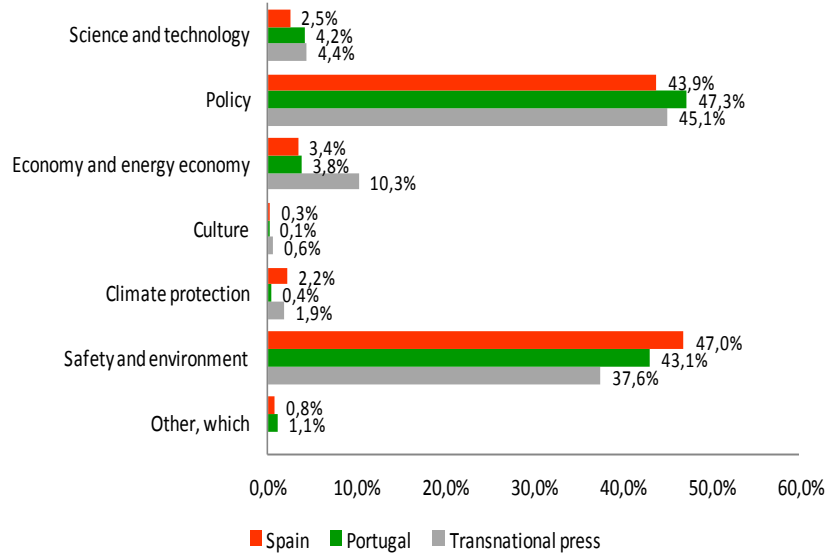

Fig. 4. Thematic areas covered in articles with nuclear energy related content

IV. CONFRONTATION BETWEEN FUSION AND FISSION IN THE MEDIA - ATTITUDES AND VALUATIONS

Most actors mentioned or quoted in articles with fusion related content in all studied areas are scientists, except in the Spanish print media where representatives of industry are major players. (Schmidt et al, 2013b). 


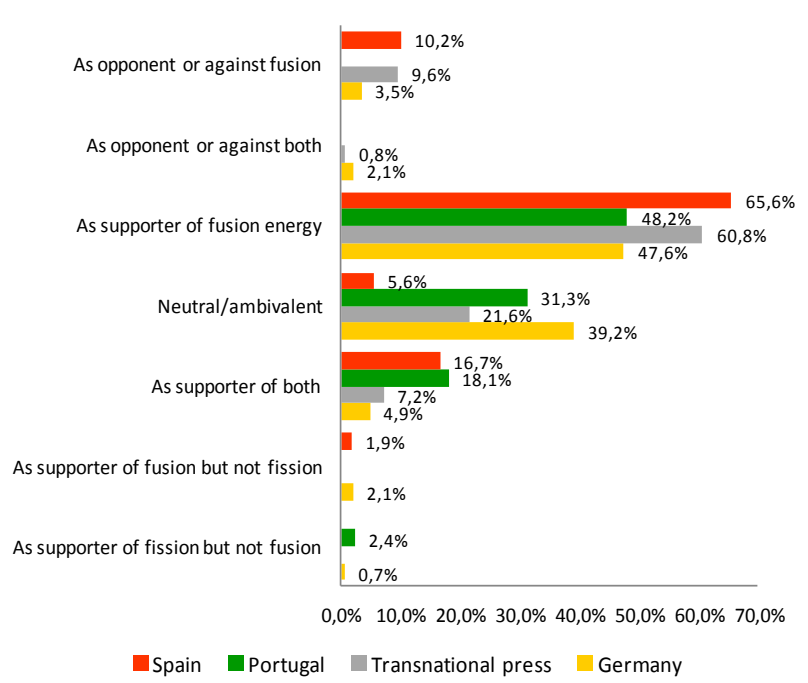

Fig. 5. Position manifested by actors about fusion in articles with fusion energy related content.

Most actors state their support to fusion energy, especially in Spanish (65\%) and transnational print media $(60 \%)$. Neutral or ambivalent positions are mainly found in German and Portuguese print media (Figure 5), while actors that oppose fusion are very few. Supporters of both fusion and fission are found in every study area (with a higher proportion of records in Spanish and Portuguese print media); the very few opponents of both technologies are found only in articles published in Germany and in the transnational print media. Records of supporters of fusion but not fission or, otherwise, supporters of fission but not fusion are residual, which indicates that the majority of actors clearly dissociate both technologies (Schmidt et al, 2013b).

Politicians are the main actors involved in media discourse about nuclear energy in all study areas. (Schmidt et al, 2013b). Supporters of fission prevail in all study areas, especially in Portugal where they represent almost half of actors that take a specific position over nuclear energy (where there are no nuclear power plants but numerous attempts to implement at least one) (Figure 6). Opponents of fission are found mainly in the Spanish press. In fact, it is only in Spain that we identify polarized positions towards fission and that opponents are dominant in comparison to supporters. Neutral or ambivalent positions can be found in every media context but prevail in the transnational. We may say that the predominant characteristic of actors' attitudes towards fission is signalled by the balance between positive and neutral attitudes in the transnational and Portuguese press contexts, whereas in the Spanish there is a divide between supporting and opposing attitudes, making it more radicalized. Supporters of fusion and fission as well as opponents to both technologies are a minority in print media news about nuclear energy. The same can be stated with respect to supporters of fusion but not fission or, otherwise, supporters of fission but not fusion. This seems to be an important characteristic of media discourse regarding nuclear fission, since it indicates that fusion and fission are in any case strongly dissociated (Schmidt et al, 2013b).

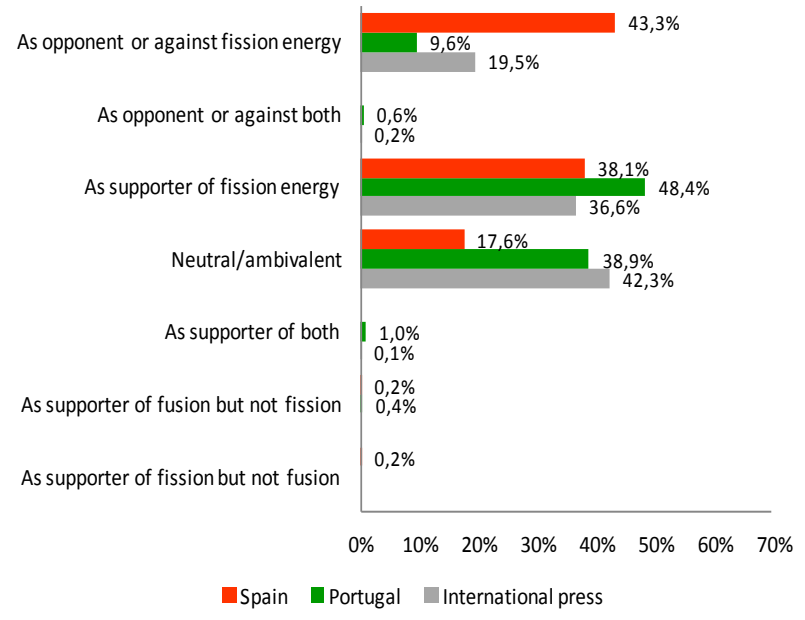

Fig. 6. Position manifested by actors about nuclear energy in articles with nuclear energy related content.

The quest for fusion energy - between hope and disbelieve

Positive statements on fusion prevail in all study areas, especially in Portugal $(71,7 \%)$, Spain $(61,8 \%)$ and in transnational print media $(60,3 \%)$ and less in Germany $(48,4 \%)$, where it is possible to find a considerable yet not predominant number of records $(33,6 \%)$ that portray nuclear fusion in a negative way.

Qualitative analysis provided a more clear insight on the image construction of fusion energy. In the current stage of research, fusion is presented as a great challenge for scientists but not as much for politicians and stakeholders. Ambiguous insights are 
particularly disclosed in the transnational print media where fusion is, on one hand, compared to outstanding collective enterprises such as medieval cathedrals, the Apollo Program and the Manhattan Project and, on the other hand, compared to desperate quests such as El Dorado or the Holy Grail (Sojak, Afeltowicz, Stankiewicz, 2013).

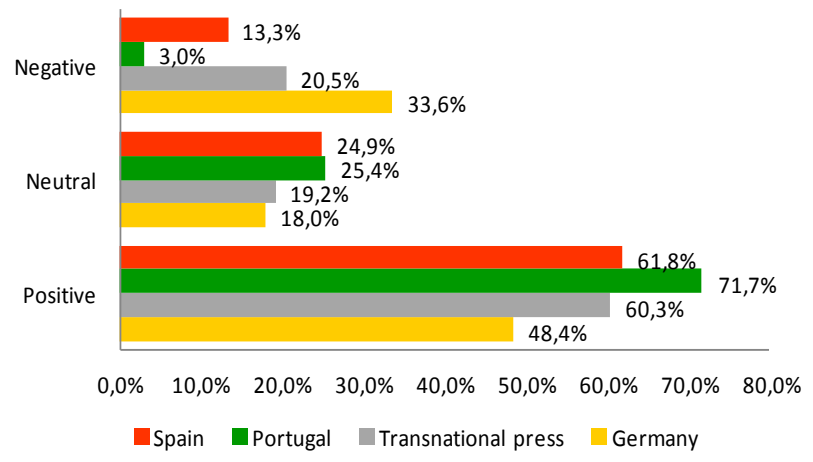

Fig. 7. Evaluation of fusion in articles with fusion energy related content.

An eloquent example of such views about nuclear fusion research is given by an article published by the International Herald Tribune - "A crusade to achieve what had eluded thousands of other scientists" (International Herald Tribune, 2010) (Sojak, Afeltowicz, Stankiewicz, 2013: 44): The Sun metaphor (artificial replication of fusion energy that occurs within the Sun) is a common and powerful symbolic reference, which contributes to associate fusion technology with a clean, safe and unlimited source of energy. Technological feasibility of fusion is the subject more vividly discussed in the articles. Arguments presented are rather very optimistic "The promise is virtually unlimited amounts of energy from abundantly available sources (International Herald Tribune, 2009) (Sojak, Afeltowicz, Stankiewicz, 2013: 46); cautiously positive - "Ignition may eventually be possible. But there's still much to learn." (International Herald Tribune, 2009) (Sojak, Afeltowicz, Stankiewicz, 2013: 47); or conveyed with irony and ridicule - "The old joke has it, fusion is the power of the future- and always will be" (The Economist, 2011); or "The Decades - old mantra fusion is only 20 (or 30 or 50) years away - remains wishful thinking at its best" (IHT, 2010) or even "NAIF - National Almost Ignition Facility" (Sojak, Afeltowicz, Stankiewicz, 2013: 47). Some scientists of the field responded to this saying that mankind's great projects are always hard to achieve, pointing as an example the "Cathedral Church of Saint John the Divine", in Manhattan, that "was still under construction after more than a century..." (IHT 2009). Cleanliness and safety are not so much discussed in the International media; however, the ideas that fusion might be an unlimited and abundant energy source, as well as a way to solve the nuclear waste problem, have been diffused. Economic costs of fusion for such a long term result are the main reasons for criticism. These refer to costs associated with the funding of ITER in national media contexts (Germany, Portugal and Spain) or with other fusion large experiment facilities such as NIF (transnational print media), a situation that is aggravated at a time of increasing scarcity of funds for scientific research.

\section{Evaluation of nuclear fission}

Nuclear fission is negatively evaluated in more than a half of the cases both in the Portuguese $(57,4 \%)$ and Spanish print media $53,4 \%$ ). In the transnational print media negative valuations are attenuated by a slight percentage of positive $(30,4 \%)$ and neutral statements $(22,3 \%)$.

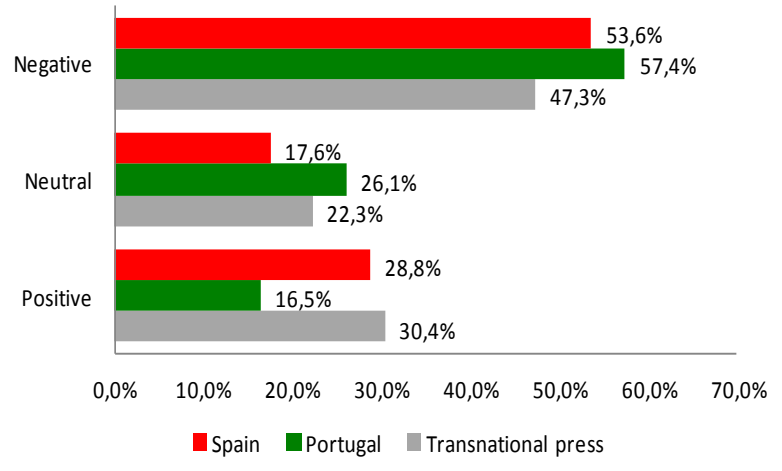

Fig. 8. Evaluation of fission in articles with nuclear energy related content.

This negative association is linked to a great variety of features, most of all to safety, cleanliness, costs of research and of power plants as well as possible military use or proliferation risks of nuclear technology. In contrast, fission is positively associated when compared to fossil fuels or whenever some of 
its main characteristics such as the warranty of supplying great amounts of energy, climate neutrality, energy abundance and, to a lower degree, its cost competitiveness are debated in the articles.

Climate neutrality and warranty of supply are somehow appraised both in Spanish and transnational newspapers, while energy source limits and fission properties in comparison to fossil fuels are the most highly evaluated items in Portuguese titles. Although fission is more positively evaluated when confronted with fossil fuels in all study areas, it is negatively or neutrally evaluated with regard to renewable sources, which means that nuclear energy may be considered a good alternative to fossil fuels (particularly when the subject of discussion is climate change) and conversely, a less acceptable alternative when renewables are also addressed as such.

\section{THE 'FUKUSHIMA EFFECT' - MEDIA COVERAGE OF FUSION AND NUCLEAR FISSION WITH RELATION TO FUKUSHIMA}

The Fukushima accident overall is not associated with fusion energy. In Spain, the majority of articles that mention Fukushima are news in brief and opinion columns, published by nationwide quality newspapers where fusion is addressed in the context of nuclear energy or fission and evaluated in a positive way. These articles explore energy policy related themes and argue about possible alternatives to fission. In Germany, most of the articles that address the accident are opinion columns published by nationwide quality newspapers, where fusion is addressed in the context of fission and particularly with regard to the country's energy policy. Here again, fusion is positively evaluated especially as an alternative to fission. In Portugal, the accident is mentioned mainly in interviews published by nationwide quality newspapers where fusion is positively addressed in the context of energy scenarios including the future of nuclear technology. As for the transnational print media, Fukushima is primary referred to in reportages published by titles such as The Washington Post and The International Herald Tribune; research projects and results of fusion technology are the main subject of such articles where fusion is addressed with a positive stance, which reinforces the idea that virtually there was no negative impact of the accident on the image of nuclear fusion.

The accident in Fukushima is otherwise paramount in articles about nuclear energy in Spanish, Portuguese and transnational print media, accounting for over than half of the sampled articles in each case study. In Spain and Portugal, these articles are mainly news in brief published by nationwide quality and popular newspapers, where fission is the core subject of discussion. The accident is essentially related to questions such as risk management and safety practices which in the case of Fukushima have failed, placing fission technology under strong criticism as it is frequently addressed in a negative way. In the transnational print media, Fukushima is primarily mentioned in reportages and opinion columns where fission technology is the core subject, the majority of which published by The New York Times, The Economist and The Guardian. These articles address fission technology mainly in a negative way (although there is a considerable number of articles where it is neutrally debated), and focus on the relationship between the accident and the guidelines of present and future energy policies and energy development scenarios of several countries.

Figure 9 illustrates the linkage between Fukushima and media coverage of nuclear fission. Nuclear energy was covered to a larger extent after the accident in Fukushima in all study areas; so we can state that the accident had a homogeneous impact in media coverage of nuclear energy (Schmidt et.al., 2013b: 35).

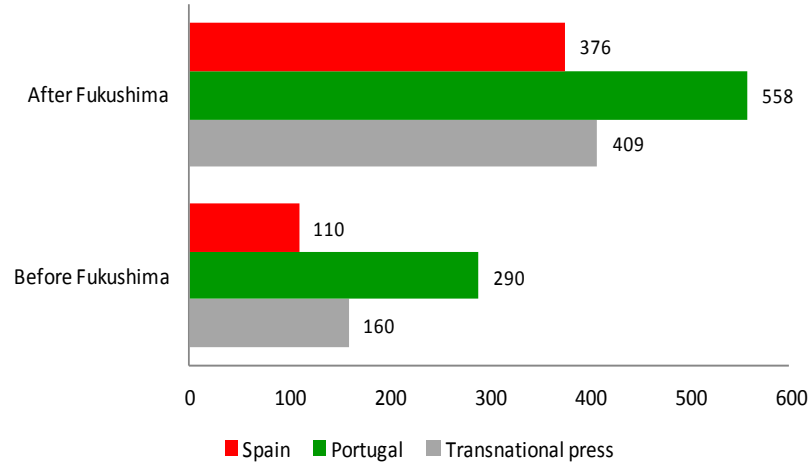

Fig. 9. Percentage of article with nuclear energy related content published before and after Fukushima accident.

After the accident in Fukushima negative valuations of nuclear energy increased in Portugal and Spain, while positive valuations decreased. Neutral valuations did not change much. In transnational media context both positive and negative evaluations increased, which indicates a polarization of judgments about nuclear energy (Table 1). Overall, we may say that nuclear energy was already negatively portrayed 
by the media before the nuclear accident in Fukushima, a fact that became more visible afterwards (Schmidt et.al., 2013b). Regarding transnational press the proportion of articles with a negative stance increased after the accident, mainly those related to cleanliness and safety. The number of neutral articles increased as well, indicating a general higher interest over these subjects.

\begin{tabular}{lcccccc} 
& \multicolumn{2}{l}{$\begin{array}{l}\text { Transnational } \\
\text { print media }\end{array}$} & Portugal & & \multicolumn{2}{l}{ Spain } \\
& Before & After & Before & After & Before & After \\
& & & & & & \\
Positive & $38,4 \%$ & $41,2 \%$ & $25,6 \%$ & $13,8 \%$ & $47,5 \%$ & $24,6 \%$ \\
Neutral & $28,3 \%$ & $20,4 \%$ & $28,5 \%$ & $25,4 \%$ & $16,1 \%$ & $17,6 \%$ \\
Negative & $33,3 \%$ & $38,4 \%$ & $45,9 \%$ & $60,8 \%$ & $36,3 \%$ & $57,7 \%$
\end{tabular}

Table 1. Image of nuclear energy based on various fission-related costs/benefits before and after Fukushima. Source: Schmidt et al, 2013b.

\section{CONCLUSIONS}

There was no evidence that the accident in Fukushima had a specific effect on media coverage of fusion energy. The number of published articles with fusion related content evolved independently from public attention given to the accident in Japan. In fact, the analysis indicates that the public discourse on fusion is constructed mainly around research challenges, clamorous events and scientific and technological achievements, rather than energy policy debate, climate protection or future economic compensations of fusion research. However, there are some differences when comparing the various media contexts. We found that German press published more articles than Portuguese, Spanish and transnational print media in the period between one year before and one year after Fukushima, not as a result of the accident itself, but rather as a consequence of a more lively and continuing public debate about fusion in Germany, where the decision to terminate fission propelled the idea of fusion as an alternative, which also became a matter of concern regarding the future of European research financing in this sector (Schmidt et al, 2013b).
Before the Fukushima accident, the thematic content of the articles in Germany concentrated on research questions and science policy in a mostly positive way. After Fukushima, energy policy evolved as a main thematic subject when talking about fusion, and the valuation of fusion tended towards stronger polarization: the neutral approach declined and extreme valuations grew (Milch and Sieber, 2013). Generally the most positive aspects underline fusion as a possible energy alternative to fission, and also warranty of supply, safety and cleanliness. The most negative statements concern fusion properties in comparison to renewables, fusion as a long-term option and power plant costs. In the English language articles addressing the transnational elite, the Fukushima accident impact on fusion energy is minor - as can be noted by a slight decrease from a positive to more neutral/balanced/ambivalent valuation (Sojak, Afeltowicz, Stankiewicz, 2013).

The Fukushima accident had otherwise a significant impact on media coverage of nuclear fission. The number of articles published in Portugal, Spain and transnational print media scaled up after the accident (given the fact that Germany was not analysed), but only for a limited period of time (first and second quarters of 2011). From the third quarter of 2011 onwards, previous trends in the amount of news about fission published in all print media contexts were re-established.

The major effect of Fukushima in thematic framing of nuclear energy was a shift in focus from routine issues concerning nuclear energy (such as military use, waste, energy policy, etc.), to accidents and emergencies, security, risk management or environmental risks associated with nuclear disasters. Only a few months after the accident, it ceased to be the keynote of media coverage, opening the way to other sorts of subjects more regularly incorporated in media agendas with respect to nuclear energy (Schmidt et al, 2013b).

Politicians are the main actors involved in the discourse framing of fission, which conforms to prevailing political based themes presented in the articles. These actors emerge from various segments of the political sphere, such as national and foreign governments, national and foreign political parties or EU organizations. There are some references to scientists (transnational print media), representatives of industry (Spain and transnational), environmental activists (Spain) and officials (Portugal and 
transnational contexts), but they play a minor role when covering nuclear energy (Schmidt et al, 2013b).

Before Fukushima, the public discourse conveyed by key actors about fission was much more positive and/or neutral compared to after the accident, when its negative accent grew up. In fact, among actors mentioned by the media, there were many more supporters of fission than opponents, except in Spain where opponents always prevail (before and after Fukushima). Neutral or ambivalent positioned actors were also numerous, especially in the transnational media context (Schmidt et al, 2013b).

However, whereas actors tend to be more neutral or positive, the image of nuclear fission covered by the media is, in general, more negative than positive, deteriorating substantially after the Fukushima accident (Schmidt et al, 2013b). Regarding transnational press, some months after the accident the discourse underwent a polarization but followed a different pattern depending on the geographic origin of the publications. In the US newspapers and magazines (mostly International Herald Tribune) nuclear fission tended to be debated in a less problematic way (which does not mean that it is considered a harmless technology), especially in the context of clean and climate neutral technologies that also include renewables. In British titles, the debate on nuclear fission is more critical focusing on whether political and social support of this technology should be maintained in the future, taking into account its most dangerous outcomes such as the nuclear accident in Fukushima (Sojak, Afeltowicz, Stankiewicz, 2013)

The cost/benefit balance for nuclear fission in the media is negative: safety, cleanliness, costs of power plants and military use are the most negatively assessed dimensions of nuclear energy. Some advantages are underlined when comparing fission properties to fossil fuels, or when fission is discussed in the context of climate change mitigation. Energy source limits and warranty of supply are also benefits (the main ones) attributed to fission energy (Schmidt et al, 2013b).

The "shock wave" that spread across the world after Fukushima threw some shadows over the future of nuclear technology. Nuclear fusion is considered an important alternative to traditional nuclear energy safe and unlimited -, but too costly and postponed (too far-off) for the current urgencies; almost a fiction: a 'Holy Grail' as some transnational newspapers conveyed with irony. Nuclear fission was directly and profoundly affected by the accident in Fukushima, and aside from political options for the future regarding the support of the nuclear industry, a more negative and pessimistic view of nuclear energy emerged after Fukushima.

\section{FUNDING}

Data presented in this paper was part of a report prepared for the European Fusion Development Agreement (EFDA) Work programme 2012 WP12-SERACIF-1 with its financial support through the IST-UL in the case of Portugal. EFDA does not endorse or take responsibility for the content of this paper.

\section{ACKNOWLEDGEMENTS}

Four teams contributed to data collection and analysis: in Portugal the team was composed of Luísa Schmidt (coordination), Ana Horta, Sérgio Pereira and Carla Oliveira, from the Instituto de Ciências Sociais, Universidade de Lisboa; in Spain, by Ana Prades and Christian Oltra from the Centro de Investigaciones Energéticas, Medioambientales y Tecnológicas (CIEMAT); in Poland, by Radosław Sojak, tukasz Afeltowicz and Piotr Stankiewicz, from the Institute of Sociology, Nicolaus Copernicus University; and in Germany, by Isabella Milch and Julia Sieber, from the Max-Planck-Institut für Plasmaphysik. The authors are grateful to their colleagues for their valuable work and to Magdalena Gadomska for her comments.

\section{FCT UID/SOC/50012/2013 FCT}

\section{REFERENCES}

[1] Bang (2010) Energy security and climate change concerns: Triggers for energy policy change in the United States?, Energy Policy, 38(4): 1645-1653

[2] Borrelli G (2004) Reports for EFDA SERF.

[3] Eurobarometer (2007) Special Eurobarometer on Energy Technologies: Knowledge, Perception, Measures. 262/Wave 65.3 TNS Opinion and Social.

[4] European Commission (2012) Communication from the commission to the council and the European Parliament on the comprehensive risk and safety assessments ("stress tests") of nuclear power plants in the European Union and related activities. Brussels, COM(2012) 571 final.

[5] Flynn J (2003) Nuclear stigma. In Pidgeon N Kasperson RE and Slovic $\mathrm{P}$ (eds) The Social Amplification of Risk. Cambrigde: Cambrigde University Press, 326-352.

[6] Gamson WA and Modigliani A (1989) Media discourse and public opinion on nuclear power: A constructionist approach. American Journal of Sociology 95(1): 1-37.

[7] Goffman E (1974) Frame Analysis: an essay on the organization of experience. London: Harper and Row. 
[8] Grove-White R (2005) Uncertainty, environmental policy and social learning. Environmental Education Research 11(1): 21-24.

[9] Hobman E and Asworth P (2013) Public support for energy sources and related technologies: the impact of simple information provision. Energy Policy 63: 862-869.

[10] Horlick-Jones T Prades A Espluga J (2012) Investigating the degree of 'stigma' associated with nuclear energy technologies: a cross-cultural examination of the case of fusion power. Public Understanding of Science 21(5): 514-533.

[11] Jasanoff S (2005) Designs of Nature. Princeton: Princeton University Press.

[12] Macnamara J (2005) Media content analysis: Its uses, benefits and Best Practice Methodology. Asia Pacific Public Relations Journal 6(1): $1-34$.

[13] Milch I and Sieber J (2013) Media discourse on fusion energy in Germany before and after the Fukushima accident. Unpublished report prepared for EFDA: WP12-SER-ACIF-1-02/IPPLM/PS by MaxPlanck-Institut für Plasmaphysik.

[14] Nisbet M and Lewenstein B (2002) Biotechnology and the American media: the policy process and the elite press, 1970 to 1999 . Science Communication 23(4): 359-391.

[15] Oltra C and Prades A (2013) Spanish public discourse on nuclear energy after Fukushima. Unpublished report prepared for EFDA: WP12-SER-ACIF-1-01/CIEMAT/BS by Centro de Investigaciones Energéticas, Medioambientales y Tecnológicas.

[16] Prades A Horlick-Jones T Oltra C and Navajas J (2007) Background review and preparation of the research methodology. Investigating lay understanding and reasoning about fusion technology. Report prepared for EFDA by CIEMAT and Cardiff University.

[17] Sailor WC D Bondansky C Braun S Fetter B Zwannn (2005) A Nuclear Solution to Climate Change? Science 288 (5469)

[18] Schmidt L Horta A Oliveira C Pereira S (2013a) Portuguese media discourse on nuclear energy before and after Fukushima. Unpublished report for EFDA: WP12-SER-ACIF-1-01/IST/PS by Instituto de Ciências Sociais da Universidade de Lisboa..

[19] Schmidt L Horta A Oliveira C Pereira S (2013b) Public Discourse on Nuclear Energy before and after Fukushima. Report for Task Agreement. Unpublished report for EFDA: WP12-SER-ACIF-1 by Instituto de Ciências Sociais da Universidade de Lisboa.

[20] Slovic, P B. Fishoff S. Lichtenstein (2002) Rating the risks. In The Perceptions of Risk. P. Slovic, London: Earthscan: 104-120.

[21] Sojak R Afeltowicz L Stankiewicz P (2013) Transnational media discourse on nuclear energy before and after the Fukushima accident. Unpublished report prepared for EFDA: WP12-SER-ACIF-101/IPP/PS by Nicolaus Copernicus University (NCU).

[22] Topçu S (2008) Confronting nuclear risks: counter-expertise as politics within the French nuclear energy debate. Nature and Culture 3(2): $225-245$.

[23] World Energy Council (2012) World Energy Perspective: Nuclear Energy One Year After Fukushima. London: Regency Hous 
